\title{
O LUGAR DO CORDEL NO LIVRO DIDÁTICO: REFLEXŌES E ANÁLISE
}

\section{THE PLACE OF CORDEL LITERATURE IN THE TEXTB00K: REFLECTIONS AND ANALYSIS}

\author{
Márcia Regina Curado Pereira Mariano² \\ Francisca Amanda dos Santos ${ }^{3}$
}

RESUMO: O presente trabalho objetiva refletir sobre o espaço destinado à literatura de cordel no livro didático, a partir da análise de parte de uma unidade do livro Português Linguagens, de William Cereja e Thereza Cochar Magalhães, como também relacionar tal abordagem com as práticas de leitura e escrita da língua materna. Para isso, adotamos a perspectiva sociointeracionista de linguagem com base em Bakhtin (2003); considerações linguísticas e discursivas com Fiorin (2002) e Orlandi (2012); Pfeiffer (2003) e Serrani (2005) para a discussão sobre leitura, escrita e ensino de língua. Ademais, apresentamos algumas proposições de Marinho e Pinheiro (2012) em relação ao trabalho com o cordel em sala de aula e o estudo crítico realizado por Luciano (2012) sobre essa literatura. Por fim, observamos como o cordel ainda ocupa um lugar secundário no livro didático analisado, o que pode apontar para uma desvalorização dessa literatura e também de nossa cultura no ensino de Língua Portuguesa.

Palavras-chave: Cordel. Sala de aula. Livro didático.

ABSTRACT: The present work aims to reflect on the space reserved to the cordel literature in textbooks by analysing part of a unit from the book Português Linguagens, by William Cereja and Thereza Cochar Magalhães, relating such an approach to reading and writing practices. For this, we adopted the socio-interactionist perspective of language based on Bakhtin (2003); linguistics and discursives considerations of Fiorin (2002) and Orlandi (2012); Pfeiffer (2003) and Serrani (2005) about reading, writing and language teaching. In addition, some of the propositions of Marinho and Pinheiro (2012) are presented on the work of cordel literature in the

\footnotetext{
${ }^{1}$ Artigo recebido em 20/02/2019 e aceito para publicação em 20/05/2019.

2 Doutora em Língua Portuguesa pela Universidade de São Paulo (USP); Professora Adjunta do Departamento de Letras do campus de Itabaiana da Universidade Federal de Sergipe (UFS); docente no Programa de Pós-graduação em Letras e no Mestrado Profissional em Letras (Profletras) na mesma instituição. E-mail: ma.rcpmariano@gmail.com.

${ }^{3}$ Mestranda do Programa de Mestrado Profissional em Letras (Profletras/UFS. Professora da Rede Estadual de Ensino de Sergipe. E-mail: chicamanda.letras@hotmail.com.
} 
classroom and a critical study by Luciano (2012) about this literature. Finally, we observed how the cordel literature is placed in a secondary role in the analyzed textbook, thus pointing to a devaluation of this literature and its culture in the teaching of Portuguese Language.

Keywords: Cordel literature. Classroom environment. Textbook.

O ensino e a aprendizagem de leitura, compreensão e produção de textos têm sido abordados em diversos estudos e sob diversas perspectivas teóricas, como os de Guimarães (2013) e Orlandi (2012), aqui retomados, dentre outros. Neste nosso trabalho, propomos contribuir com essas discussões, refletindo, especificamente, sobre o lugar ocupado e destinado à literatura de cordel no livro didático. Com esse intuito, apresentamos a análise de parte de uma unidade do livro didático de Língua Portuguesa Português Linguagens, de William Cereja e Thereza Cochar Magalhães (2015), destinado ao 7음 ano do Ensino Fundamental.

O livro didático é usado, muitas vezes, como o principal ou único material de apoio ao professor no ensino-aprendizagem; concebido para ser constituído por textos de natureza variada, selecionados de acordo com as demandas de cada série que compõe os níveis de ensino, tendo em vista certas expectativas do público discente e atendendo a parâmetros nacionais e institucionais, esse complexo constitui um discurso didático autorizado que ganha credibilidade e aceitação da maioria das instituições e dos docentes.

Nesse sentido, Pfeiffer (2003) nos apresenta três diferentes posicionamentos de professores em relação a metodologias de ensino: o tradicional, no qual o livro didático é adotado, priorizando-se a prática em detrimento das metodologias; o intermediário, em que o livro didático é usado apenas como orientador da sequência de conteúdo das aulas; e, por último, um mais radical, em que o livro é banido por completo.

Cientes e experientes de/com o descaso e a desvalorização do professor no Brasil, sabemos que o ensino tradicional e o uso exclusivo do livro didático ainda são frequentes, pois facilitam a vida de docentes sobrecarregados de horas-aula e salas lotadas, que precisam, muitas vezes, para sobreviver, acumular cargos em diferentes turnos e escolas. Nesse quadro, nem sempre o professor observa se há lacunas nos conteúdos ou se há discursos nos livros didáticos não apropriados ou claros. Desta maneira, o 
professor corre o risco de se tornar um mero repetidor, algumas vezes de discursos preconceituosos, excludentes, ultrapassados ou descontextualizados, tendo em vista a realidade do aluno, etc.

Do ponto de vista do sociointeracionismo, o discurso é entendido como meio de interação entre sujeitos sociohistoricamente situados, dessa forma, no contexto da dinâmica discursiva que se dá na sala de aula, evidencia-se de forma significativa o dialogismo defendido na teoria bakhtiniana: "O professor apropria-se do discurso do cientista, repetindo, portanto, discursos preexistentes. O aluno acolhe o discurso do professor, assimilando-o, interpretando-o, dando-Ihe resposta." (GUIMARÃES, 2013, p. 94).

Num país tão extenso e plural como o nosso - embora saibamos que essas características não são exclusivas do Brasil -, no entanto, faz-se necessário problematizarmos a pretensa unicidade de língua e cultura que muitas vezes é reforçada nos manuais didáticos, bem como os discursos neles presentes, já que poderão ser apenas repetidos e aceitos como verdadeiros. Quando um único ponto de vista é imposto e/ou tomado como único e verdadeiro, passa-se rapidamente de um discurso autorizado para um discurso autoritário. Portanto, o ensino-aprendizagem não pode contar apenas com o discurso do livro didático, mas deve ser construído num diálogo entre este (quando adotado pela escola), professor e alunos (além dos pais, da comunidade...).

Dentro dessa problemática, é preciso, enquanto docentes, termos consciência dessa nossa heterogeneidade linguística e cultural; sopesar a supremacia do livro didático; buscar autonomia, junto a uma eterna busca por conhecimento, para atender às expectativas de língua e linguagem de nossos alunos e tentar garantir que os discursos, venham de onde vier, sejam recebidos e interpretados de forma crítica por eles.

Num contexto nordestino, preocupar-se com o espaço dado à literatura de cordel no livro didático é preocupar-se com a representação de nossa cultura, de nossa história; é adotar uma concepção social de língua e linguagem, por isso nosso interesse.

\section{Linguagem, língua e ensino}

No livro Linguagem e ideologia, Fiorin (2002) menciona duas maneiras de se compreender e de se estudar o fenômeno linguístico: 
ocupar-se da análise interna da linguagem ou priorizar a correlação entre fatos linguísticos e fenômenos de ordem social. Concordando com a segunda abordagem, segundo este autor, a linguagem é "um fenômeno extremamente complexo, que pode ser estudado de múltiplos pontos de vista, pois pertence a diferentes domínios. É, ao mesmo tempo, individual e social, física, fisiológica e psíquica." (FIORIN, 2002, p. 8).

Bakhtin, por sua vez, posicionando-se contra a primeira concepção de linguagem apontada por Fiorin, o objetivismo abstrato herdeiro da teoria saussuriana, já afirmava, em meados da década de 1920, que todos os ramos da atividade humana ligam-se ao uso da linguagem. Esses usos acontecem de múltiplas formas através de enunciados orais e escritos, que refletem as condições próprias e os objetivos dos ramos em que se inserem por meio do conteúdo/temática, do estilo linguístico e da composição. Em outras palavras, "cada campo de utilização da língua elabora seus tipos relativamente estáveis de enunciados, os quais denominamos gêneros do discurso." (BAKHTIN, 2003, p. 262; grifos do autor).

Trazendo o conceito de gêneros para o ensino de língua, vemos em Serrani (2005) que as abordagens que se baseiam nas perspectivas do discurso indicam uma reação frente a uma perspectiva comunicativista e utilitarista da linguagem. Nesse sentido, a literatura presente nas aulas faz parte de uma ampliação do conjunto de gêneros trabalhados (gêneros discursivos mais gêneros literários), e, consequentemente, aumentaria a capacidade textual-discursiva dos alunos.

É evidente que não somente exemplos de textos jornalísticos ou outros discursos não literários são importantes na formação linguística e educacional. Assim a proposta é a de incluir cada vez mais textos literários nas aulas de língua, com um trabalho discursivo-contrastivo intra e interlinguístico, em que diversas práticas verbais (leitura, escrita, produção oral, escuta e, quando couber, tradução) estejam inter-relacionadas. (SERRANI, 2005, p.47)

De acordo com Pfeiffer (2003), muito se discute sobre a dificuldade de se desenvolver o hábito de leitura nos alunos, todavia, é preciso considerar a inserção deles numa dinâmica social que determina a configuração de qualquer sujeito-leitor. Sendo assim, o perfil do leitor- 
escolar que se espera alcançar é também o resultado de representações imaginárias que discentes e docentes têm acerca do que seria um bom leitor.

Segundo Orlandi (2012), a leitura passa por um processo de legitimação, de modo que umas leituras são consideradas mais legítimas que outras, e, na escola, o cenário não é diferente:

No interior do processo de legitimação, o professor retoma, em seu trabalho pedagógico, uma leitura considerada ideal, e que tem como modelo a de um crítico. Muitas vezes a leitura ideal do professor é fornecida pelo livro didático. A autoridade imediata, nesse caso, é o autor do livro didático adotado que, por sua vez, pode-se ter modelado no crítico. (ORLANDI, 2012, p.115).

Acerca da relação entre leitura e escrita, Orlandi (2012) reconhece que a primeira constitui a segunda, embora o relacionamento entre as duas não seja automático, ou seja, ler muito nem sempre resulta em escrever satisfatoriamente. Isso ocorre porque ambos são processos distintos e refletem formas diversas de contato com a linguagem. Para a autora, numa proposta escolar, podem-se observar dois aspectos referentes ao binômio leitura/escrita: a leitura como fonte para a escrita - "o que escrever" e a leitura como modelo para a escrita - "o como se escrever" (ORLANDI, 2012, p.119-120).

Baseadas em nossa experiência docente, percebemos que, dentre todos os incontáveis gêneros existentes, discursivos e literários, alguns parecem ter mais espaço nos livros didáticos do que outros. Quanto aos gêneros discursivos, alguns parecem ter lugar cativo nos manuais didáticos, como a reportagem e a notícia, enquanto outros, mais utilizados no dia a dia, são esquecidos. Dentre os literários, além da presença constante de determinados gêneros, como o conto, ainda há o predomínio dos cânones da literatura. Nesse meio, contudo, defendemos que devem estar presentes também aqueles gêneros que servem ao uso cotidiano da linguagem, à organização social, à persuasão, e aqueles que trazem marcas específicas das diferentes regiões, que nos permitam conhecer nosso país e nossa já lembrada pluralidade.

Em uma rápida sondagem com nossos alunos do 6으 ano de uma escola pública de Aracaju-SE, para saber qual seu nível de conhecimento 
sobre a literatura de cordel, surpreendemo-nos com o fato de que de 28 alunos 17 responderam nunca ter lido ou ouvido falar sobre cordel. Sabendo que o livro didático ainda é a principal ferramenta utilizada pelo professor, onde estaria, então, o cordel nos manuais? Se ele está presente, por que não foi visto por esses alunos?

\title{
0 cordel em sala de aula
}

Conforme Marinho e Pinheiro (2012), embora a literatura de cordel não seja destinada a um público específico, percebem-se aproximações entre esta e a atual literatura infantil brasileira:

\begin{abstract}
Há em muitos cordéis, traços como o predomínio da fantasia, inventividade ante situações inesperadas/complexas, musicalidade expressiva, caráter fabular, marcas comuns à literatura para crianças. O humor é presença marcante tanto na poesia para crianças quanto no cordel. Também um filão do cordel que o aproxima à literatura para crianças é a recriação de contos de fadas tradicionais. (MARINHO; PINHEIRO, 2012, p. 49)
\end{abstract}

Já sobre a pertinência do estudo da literatura de cordel em sala de aula, Evaristo (2001) afirma que:

[...] parece ser fundamental o estudo do cordel no contexto multicultural das cidades brasileiras, heterogêneas e multifacetadas, abrigos de diversidades que, para serem abarcadas, requerem uma ampliação do contato e o conhecimento de universos distintos. (EVARISTO, 2001, p. 139)

Para Marinho e Pinheiro (2012), é importante que a escola resgate experiências artísticas e culturais como o cordel, destacando a vivacidade, a adaptação a novos contextos socioculturais, a resistência frente ao fenômeno da cultura de massa etc., com o objetivo de que essas experiências não sejam esquecidas e possam ser divulgadas nesse ambiente.

Desse modo, os autores sugerem algumas atividades que se mostram possíveis de serem realizadas nas aulas de Língua Portuguesa; a primeira delas é a leitura oral repetida dos folhetos de cordel, a qual ajudaria a perceber o ritmo e as entonações adequadas, algo que, além de dar maior expressividade à leitura, motiva os alunos, mexe com sua 
afetividade. Ademais, o professor deve estar atento à possibilidade de encontrar, no momento da execução desse trabalho, jovens que não tiveram a oportunidade de conhecer a literatura de cordel.

Também é possível aproveitar a variedade de temas da literatura de cordel para desenvolver debates e discussões em sala de aula, através dos quais se ampliam o diálogo e o contato com diferentes visões de mundo.

A leitura de cordel permite ainda o desenrolar de outra atividade: a produção de histórias em sala, considerando que a criação literária não deve ser imposta, pois alguns alunos, apesar de gostarem de ler, podem não demonstrar o mesmo interesse pela escrita. Sobre esse assunto, Marinho e Pinheiro (2012) afirmam:

A proposta de criação tendo como estímulo um poema, uma crônica, uma notícia de jornal, uma ilustração comparece em quase todos os manuais. Trata-se de uma atividade didática que, se eventual e bem encaminhada, pode conduzir a bons resultados. (MARINHO; PINHEIRO, 2012, p. 134)

Acreditando que a leitura e a criação literária são também leituras de mundo, retomadas e releituras discursivas e afirmação identitária, como docentes num estado do nordeste brasileiro, partimos para um livro didático para observar onde está o cordel que as crianças nunca viram.

\section{0 lugar do cordel em um livro didático de Língua Portuguesa}

O livro em questão, adotado em várias escolas públicas da rede estadual em Sergipe, intitula-se Português Linguagens e é uma publicação da editora Saraiva, do ano de 2015 (9a edição). Nessa obra, dos autores Cereja e Magalhães, encontram-se, no capítulo 2 da unidade 2, na seção Produção de texto, algumas considerações sobre a literatura de cordel, dentre elas, destacam-se as seguintes, acompanhadas de nossas reflexões baseadas em Luciano (2012):

a) "o cordel é um tipo de poesia popular" (CEREJA; MAGALHÃES, 2015, p.102). Segundo Luciano (2012), essa definição sobre o cordel é desnecessária ou mesmo sem sentido, pois o que se tem é Literatura. Fomentar uma distinção entre popular e erudito seria reforçar o tratamento 
preconceituoso e excludente que as elites intelectuais oferecem àquilo que não é produzido por elas. Para o autor, não é o termo que incomoda, posto que "todo o produto literário é popular, porque vem de um povo" (LUCIANO, 2012, p. 21), mas o caráter grotesco e pejorativo que advém dele, que resulta em desvalorização.

b) "os poemas representativos desse tipo de literatura geralmente são impressos em folhetos, que são expostos pendurados em cordel (corda fina) ou barbante - daí seu nome" (CEREJA; MAGALHÃES, 2015, p.102). Luciano (2012) esclarece que a denominação literatura de cordel atribuída aos folhetos vendidos em feiras foi herdada pelos nordestinos nascidos na década de 60 do século passado. O termo firmou-se como verdadeiro, e se deve tanto à forma como era vendido o folheto quanto à apresentação física. De acordo com o autor, estudiosos como Manuel Diégues Júnior (1977), Sebastião Nunes Batista (1977), Hélder Pinheiro (2001) e Joseph Luyten (1984) repetem essa informação.

c) "o cordel teve sua origem em Portugal e, chegando ao Brasil, espalhou-se por todo o Nordeste brasileiro, onde é cultivado e muito apreciado" (CEREJA; MAGALHÃES, 2015, p. 102). Conforme Luciano (2012), folcloristas brasileiros como Luís da Câmara Cascudo (1979) e Manuel Diégues Júnior (1973) deram sua contribuição para a problemática da gênese da literatura brasileira de cordel, mostrando a ligação entre os folhetos de feira vendidos no Brasil, a partir do século XVII, com as "folhas volantes" ou "folhas soltas" de Portugal, que eram comercializadas exclusivamente por cegos. Todavia, para o referido autor, a origem e a formação histórica do cordel brasileiro "não tem qualquer ligação, exceto no nome, com a literatura de cordel portuguesa, salvo em alguns de seus motivos. A ligação é com a narrativa tradicional que vai muito além das folhas soltas." (LUCIANO, 2012, p. 42-43).

d) "A poesia de cordel é narrativa e tem uma estrutura mais ou menos padrão" (CEREJA; MAGALHÃES, 2015, p. 102). A partir da noção de gêneros literários, Luciano (2012) afirma que embora o cordel seja uma forma poética fixa, ela pode se manifestar de modos variados, sem que haja necessariamente uma pureza textual, sendo assim, o cordel narrativo pode apresentar traços líricos, dramáticos etc. Além disso, há cordéis que priorizam outros tipos textuais, como os folhetos informativos, de orientação, os de diálogo (pelejas) etc.

Em seguida o livro traz, como exemplo desse tipo de literatura, um trecho de um poema de Chico Salles, cordelista da Paraíba: 
Fragmentos do cordel $O$ barato da barata

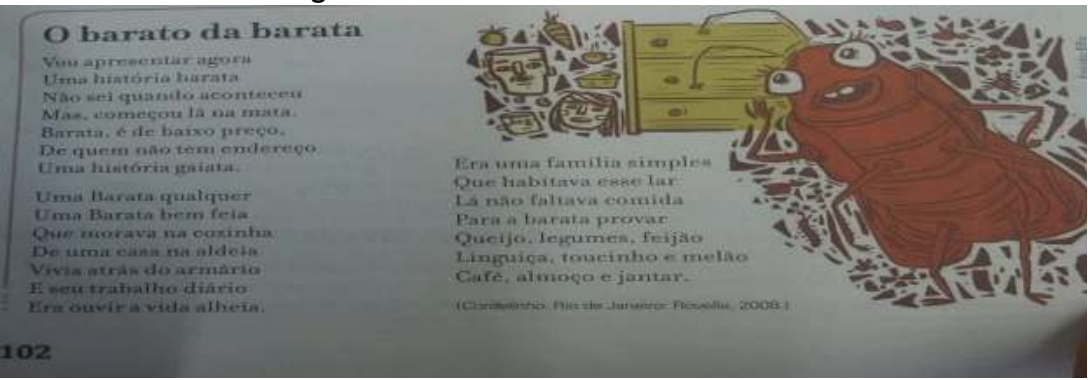

(CEREJA; MAGALHÃES, 2015, p. 102)

Além do cordel não ser o texto principal da unidade, já que é encontrado apenas na parte relativa à produção, quando ele aparece no livro didático vem fragmentado. As únicas três estrofes apresentadas não são o suficiente para que o aluno conheça as características estruturais do gênero e muito menos para que ele chegue a um sentido para esse texto. Sem desmerecer a temática desenvolvida pelo cordelista, mas o cordel escolhido também não estabelece uma relação com um dos aspectos apresentados pelo próprio livro didático: o de ter se espalhado pelo nordeste, onde é mais apreciado. $\mathrm{O}$ que, nos fragmentos expostos, remete à cultura nordestina?

A partir desse texto, são propostas algumas questões, nas quais é possível observar uma maior preocupação com o aspecto estrutural do cordel, deixando-se de abordar discussões acerca da temática, da importância cultural dessa produção etc:

1. O poema de cordel é geralmente formado por estrofes, que podem ter quatro, seis, sete ou dez versos cada uma. A mais comum é a estrofe de seis versos. No trecho do poema lido, quantos versos há em cada estrofe?

2. O poema de cordel sempre apresenta rimas, que podem variar quanto à disposição. Qual é a disposição das rimas no trecho do poema lido?

3. A maioria dos poemas de cordel tem versos de sete sílabas poéticas. A sílaba poética é diferente da sílaba comum, pois depende de como se pronuncia o verso. Assim, as vogais de palavras diferentes, quando em sequência, são unidas. Além disso, ao se fazer a contagem das sílabas poéticas, considera-se apenas a última sílaba tônica do verso. Veja: (o livro traz dois exemplos de escansão). Escreva em seu caderno a segunda estrofe do poema lido e faça a contagem das 
sílabas poéticas de cada verso. Quantas sílabas poéticas os versos têm?

Apesar de reconhecermos a importância das questões metalinguísticas no estudo do texto, e aqui especificamente das sílabas métricas nos poemas, observamos que essas não podem ser as únicas. $E$ na sequência do livro o que se destaca continua sendo o aspecto estrutural do cordel. Na subseção Agora é sua vez, são propostas quatro produções textuais concernentes à criação de poemas de cordel. A sugestão é que os alunos desenvolvam todas ou apenas algumas das propostas, que devem ser publicadas em um livro e comporão uma mostra chamada Viva a poesia viva!, de acordo com as orientações do professor.

A primeira proposta de produção textual traz duas estrofes de um cordel metalinguístico também de Chico Salles, chamado Aprendendo a cordelisar. O livro destaca que esse poema ensina a fazer um cordel, ao mesmo tempo em que fala sobre os melhores lugares do mundo. As duas estrofes focalizam o Rio de Janeiro e o Rio Grande do Norte e trazem os seguintes dois primeiros versos: Métrica em sextilhas obedecendo/o critério obrigatório das rimas. A proposta é que os alunos escrevam uma ou duas estrofes falando sobre o melhor lugar do mundo para eles e obedecendo à estrutura trazida pelo autor do cordel.

A segunda proposta, por sua vez, propõe que o aluno escolha uma história curta, já conhecida, e reconte-a em "linguagem de cordel" (o que seria uma "linguagem de cordel"?). A terceira proposta de produção textual parece valorizar um pouco mais a origem do cordel, trazendo uma temática ligada ao povo nordestino, a seca. Esse cordel, de Leandro Gomes de Barros, do início do século XX, também é o que foi representado por um número maior de estrofes, como se vê a seguir: 
Fragmentos do cordel A seca do Ceará

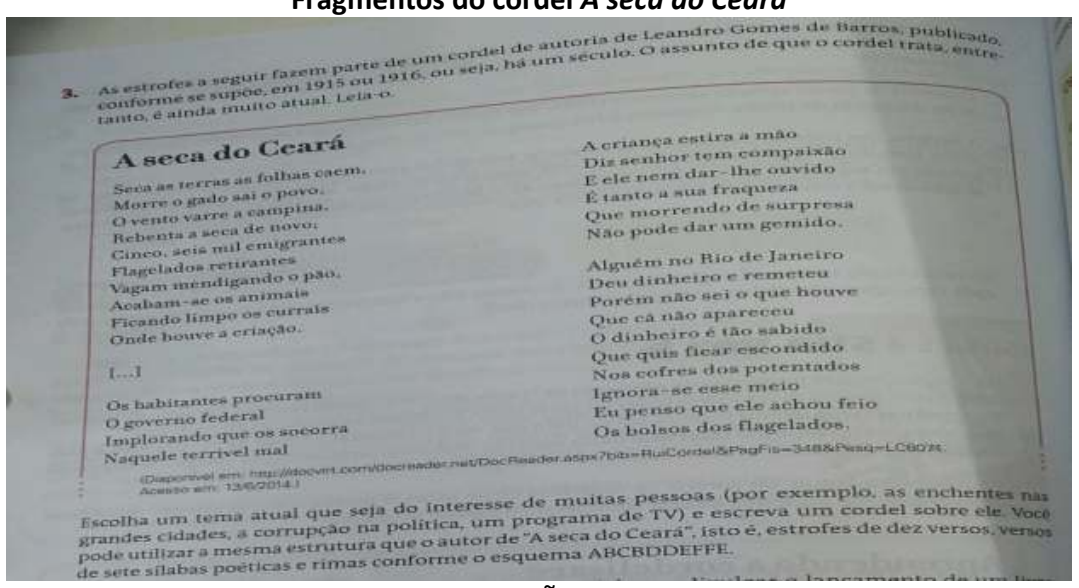

(CEREJA; MAGALHÃES, 2015, p. 104)

Aqui encontramos, talvez pela primeira vez desde que se iniciou essa parte sobre cordel no livro, uma preocupação com a temática do cordel que será produzido pelos alunos. "A seca", tema do poema apresentado, é trazida como um tema atual, apenas. Não há nem a sugestão para o professor aprofundar uma discussão sobre essa realidade, ao mesmo tempo geofísica e social, suas causas e consequências. Outros temas atuais, segundo o livro, são propostos para a produção do texto: enchentes nas grandes cidades, corrupção na política, programa de TV. No entanto, não há nenhuma sugestão de leitura ou discussão sobre esses temas. De resto, mais uma vez, orientações sobre a estrutura do cordel.

Finalmente, o livro propõe a criação de um convite para a mostra de poesia, citada no início das propostas de produção - a Viva poesia viva!. Para isso traz dois exemplos de convite em forma de cordel. Mais uma vez, destaca a estrutura de estrofes e versos.

Após as propostas de produção, fala-se um pouco, pouco mesmo, sobre as temáticas:

Os temas do cordel

Os cordéis geralmente fazem referência a fatos que interessam à população em geral (programas de TV, novas leis ou acordos políticos, personalidades, entre outros) ou a situações corriqueiras da vida diária.

Para exemplificar, são apresentadas quatro capas de folhetos de cordel. Mesmo trazendo as capas, não há nenhuma menção à xilogravura, 
arte que estampa a grande maioria dos folhetos e que tem uma função muito mais textual do que decorativa, dando ao cordel um aspecto multimodal, na medida em que seu sentido é a soma da linguagem verbal e da não-verbal, representada pela xilogravura.

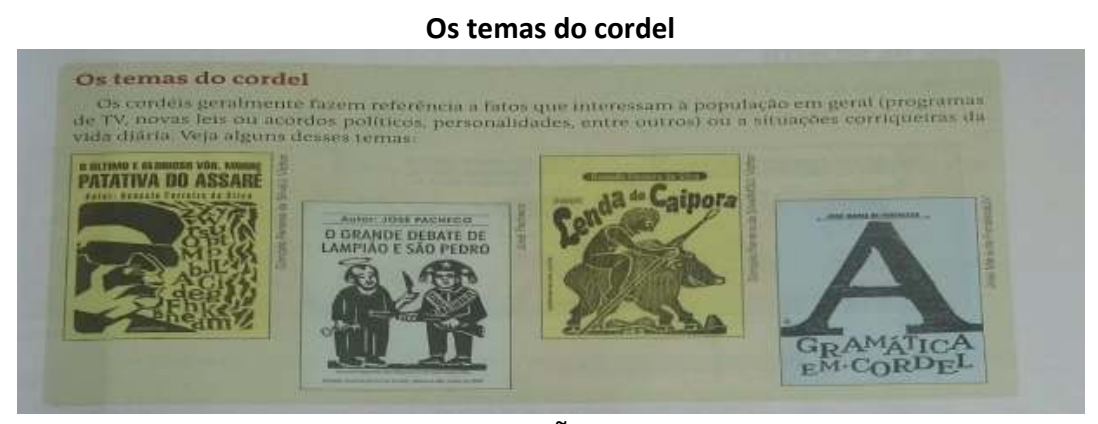

(CEREJA; MAGALHÃES, 2015, p. 105)

Por último, o livro trata de questões como planejamento do texto, revisão e reescrita, que acabam apenas retomando a preocupação com a estrutura do texto, acrescida agora da correção gramatical e ortográfica. Em momento algum há uma preocupação com o leitor desse texto. Para quem o aluno escreve? O mais perto que se chega disso é na orientação "dê um título atraente ao seu cordel" e, na revisão, observe "se o título é atraente". E nos perguntamos: atraente para quem?

\section{Consideraçồes finais}

Os gêneros discursivos permeiam a vida em sociedade, refletindose nos mais variados usos da linguagem; os gêneros literários somam-se na composição dessa dinâmica e graças às suas potencialidades discursivas e textuais devem ser tão estudados quanto os primeiros.

Nesta nossa breve pesquisa, observamos que o trabalho com o cordel em sala de aula assemelha-se, em alguns aspectos, ao tratamento dado a outros gêneros no livro didático. Mariano (2012), ao analisar uma unidade de um livro didático dos mesmos autores do livro aqui analisado, William Cereja e Thereza Cochar Magalhães, direcionado ao ensino médio, constatou, baseada nos estudos da argumentação e da retórica, que as atividades de compreensão e produção do gênero editorial centravam-se, sobretudo, na estrutura do texto e na repetição ou cópia de conteúdos. 
Nessa análise, a autora observou ainda que essa abordagem acaba por menosprezar o papel do leitor/ouvinte na construção do sentido, bem como da construção argumentativa e de outros elementos importantes para a eficácia persuasiva do texto, como sua apresentação e a presença de linguagens não-verbais.

Mendonça (2006), numa perspectiva discursiva, por sua vez, discute como os livros didáticos, escolas e professores promovem verdadeiras "políticas de fechamento", que privam os alunos de possibilidades por meio da imposição de uma única língua tida como correta, a norma-padrão escrita; de um único sentido para os textos e, por fim, de estereotipação dos gêneros a partir de modelos e esquemas, que revelam o privilégio da estrutura em detrimento do conteúdo e do dialogismo na construção de sentidos. Quanto a este último aspecto, a pesquisadora também observa a ausência de um interlocutor nas produções textuais dos alunos, que acabam sendo apenas o preenchimento de uma folha em branco para o professor avaliar a gramática e a ortografia.

Esse desconhecimento da importância do "para quem escrever" e de "o que dizer" em atividades de produção de texto já nos levam a questionar o modo como o cordel foi trabalhado na unidade do livro aqui analisada. Acresce-se a isso, no entanto, e é esse fator que nos leva ao título de nosso trabalho, o fato de que o cordel não mereceu um lugar de destaque na unidade. Pelo contrário, ele aparece apenas na seção de produção de texto, no final da unidade, sem nenhuma atividade de leitura e compreensão, acompanhado de informações vagas, algumas desatualizadas, e que podem até reforçar o preconceito em relação a esse tipo de literatura.

$\mathrm{Na}$ pouca atenção dada, importam apenas as características estruturais, esvaziando-se desse gênero o que ele tem de mais genuíno que é sua origem, sua função social e sua riqueza cultural. Relacionado mais particularmente ao povo nordestino, a desvalorização do cordel pode também reforçar discursos preconceituosos, além de não permitir um conhecimento e uma identificação do aluno dessa região sobre/com os textos trazidos pelo livro didático. Apenas relembrando, uma das atividades propostas dizia para o aluno recontar uma história em "linguagem de cordel"! Ora, o cordel, o nosso cordel, não é em língua portuguesa?

Longe de chegar a conclusões sobre o tema, acreditamos que restam ainda muitas reflexões e análises a serem feitas. Esperamos, 
contudo, ter contribuído de maneira positiva para a discussão sobre o ensino de língua materna, sobre o livro didático e sobre a importância do cordel em sala de aula. Esperamos, ainda, e principalmente, ter levantado questionamentos sobre o lugar do cordel nessa ferramenta pedagógica, a fim de que os docentes percebam essa ausência ou esse tratamento secundário dado a essa literatura e a explorem mais em suas aulas, tanto em seus aspectos literários quanto discursivos.

\section{Referências}

BAKHTIN, M. Os gêneros do discurso. In: BAKHTIN, M. Estética da criação verbal. São Paulo: Martins Fontes, 2003. p. 261-306.

CEREJA, W. R.; MAGALHÃES, T. C. Português Linguagens. 7. ano do Ensino Fundamental. 9. ed. São Paulo: Saraiva, 2015. p. 102-105.

EVARISTO, M. C. O cordel em sala de aula. In: BRANDÃO, H. N.. Gêneros do discurso na escola: mito, conto, cordel, discurso político, divulgação científica. 2. ed. São Paulo: Cortez, 2001. p. 119-184.

FIORIN, J. L. Linguagem e ideologia. 7. ed. São Paulo: Ática, 2002.

GUIMARÃES, E. Texto, discurso e ensino. São Paulo: Contexto, 2013.

LUCIANO, A. Apontamentos para uma história crítica do cordel brasileiro. Rio de Janeiro: Edições Adaga; São Paulo: Editora Luzeiro, 2012.

MARIANO, M. R. Curado Pereira Mariano. O ensino da Argumentação na antiguidade e em um livro didático atual. EID\&A - Revista Eletrônica de Estudos Integrados em Discurso e Argumentação, Ilhéus, n. 3, p. 104-116, 2012.

MARINHO, A. C.; PINHEIRO, H. O cordel no cotidiano escolar. São Paulo: Cortez, 2012.

MENDONÇA, M. C. Língua e ensino: políticas de fechamento. In: MUSSALIM, F; BENTES, A. C. (orgs.). Introdução à linguística - domínios e fronteiras. São Paulo: Cortez, 2006. p. 233-263.

ORLANDI, E. P. Discurso e leitura. 9. ed. São Paulo: Cortez, 2012.

PFEIFFER, C. C. O leitor no contexto escolar. In: ORLANDI, E. P. (org.). A leitura e os leitores. 2. ed., Campinas: Pontes, 2003. p. 87-104.

SERRANI, Silvana. Discurso e cultura na aula de língua: currículo, leitura, escrita. São Paulo: Pontes, 2005. 